\title{
Global and regional techniques for monitoring cerebral oxidative metabolism after severe traumatic brain injury
}

\author{
Alex B. Valadka, M.D., Yu Furuya, M.D., Roman Hlatky, M.D., \\ and Claudia S. Robertson, M.D. \\ Department of Neurosurgery, Baylor College of Medicine, Houston, Texas
}

\begin{abstract}
The disturbance of normal mechanisms of oxygen delivery and metabolism is a hallmark of severe traumatic brain injury (TBI). In the past, investigations into the status of cerebral oxygen metabolism depended on changes in the differences in oxygen content between arterial and jugular venous blood. The development of jugular venous oximetry permitted continuous monitoring of jugular venous oxygen saturation, thereby overcoming earlier limitations caused by intermittent sampling. Neuromonitoring techniques that utilize only jugular vein sampling provide information only about global cerebral metabolism, but direct measurement of brain tissue oxygen tension via intraparenchymal probes makes possible the assessment of regional cerebral oxygen metabolism. Regional and global neuromonitoring techniques are not competitive or mutually exclusive. Rather, they are best regarded as complementary, with each providing valuable information that has a direct bearing on patient outcomes. The authors review the currently available techniques used in the monitoring of cerebral oxidative metabolism in patients who have sustained severe TBI.
\end{abstract}

\section{KEY WORDS - arteriovenous oxygen difference - brain tissue oxygenation • jugular venous oxygen saturation - neuromonitoring • oxygen tension}

Disruption of oxygen metabolism represents one of the major physiological derangements caused by TBI. Because outcome after TBI correlates strongly with the degree of impairment of oxidative metabolism, measurements of cerebral oxygen delivery and consumption serve as valuable indicators of the status of cerebral metabolism. In this review we summarize the advantages and disadvantages of several established techniques and of newer methods of monitoring cerebral oxygenation in patients after TBI.

\section{GLOBAL CEREBRAL METABOLISM}

\section{Arteriovenous Difference of Oxygen}

This technique for the monitoring of $\mathrm{AVDO}_{2}$ is based on the difference in oxygen content between simultaneously obtained samples of blood entering and exiting the brain. Blood located anywhere within the arterial system (for example, the radial artery) can be sampled to determine the oxygen content of blood entering the brain. However, accurate sampling of blood exiting the brain requires cannulation of the jugular bulb, which contains only blood that has passed through the brain and has not yet

\footnotetext{
Abbreviations used in this paper: AVDL = arteriovenous difference of lactate; $\mathrm{AVDO}_{2}=$ arteriovenous difference of oxygen; $\mathrm{CBF}=$ cerebral blood flow; $\mathrm{CMRO}_{2}=$ cerebral metabolic rate of oxygen; $\mathrm{PbtO}_{2}=$ brain tissue oxygen tension; $\mathrm{SjvO}_{2}=$ jugular venous oxygen saturation; TBI = traumatic brain injury.
}

mixed with that from the face, neck, and other extracerebral tissues.

The relationship between $\mathrm{AVDO}, \mathrm{CBF}$, and $\mathrm{CMRO}_{2}$ (which is determined by the equation $\mathrm{CMRO}_{2}=\mathrm{AVDO}_{2} \times$ $\mathrm{CBF}^{6}$ ) is illustrated in Fig. 1. If $\mathrm{CBF}$ is coupled with $\mathrm{CMRO}_{2}$, then $\mathrm{AVDO}$, remains constant as CBF changes. ${ }^{8}$ However, if $\mathrm{CBF}$ and $\mathrm{CMRO}_{2}$ are uncoupled, then changes in $\mathrm{CBF}$ while $\mathrm{CMRO}_{2}$ remains constant, are reflected as changes in AVDO,

The relationship between $\mathrm{CBF}$ and $\mathrm{AVDO}_{2}$ becomes much less predictable when ischemia or infarct is present. These conditions can be detected by measuring the AVDL and using it to determine the lactate-oxygen index by the equation lactate-oxygen index $=-$ AVDL/AVDO. A lactate-oxygen index greater than or equal to 0.08 indicates the presence of ischemia. Except during ischemia or other pathological events characterized by an extremely low $\mathrm{CMRO}_{2}, \mathrm{CBF}$ has been shown to correlate well with $\mathrm{AVDO}_{2}$. In severely head-injured patients with an AVDO of less than $2.9 \mathrm{ml} / \mathrm{dl}$, an average CBF value of $53 \pm 18$ $\mathrm{ml} / 100 \mathrm{~g} / \mathrm{min}$ has been demonstrated; in those with an AVDO, between $2.9 \mathrm{ml} / \mathrm{dl}$ and $6.8 \mathrm{ml} / \mathrm{dl}$, an average CBF value of $42 \pm 12 \mathrm{ml} / 100 \mathrm{~g} / \mathrm{min}$ was shown; and in those with an $\mathrm{AVDO}$, greater than $6.8 \mathrm{ml} / \mathrm{dl}$ an average $\mathrm{CBF}$ value of $23 \pm 7 \mathrm{ml} / 100 \mathrm{~g} / \mathrm{min}$ was found. ${ }^{8}$

Despite the benefits of monitoring AVDO, and AVDL, these techniques have significant limitations. Sampling of cerebral oxidative metabolism in this manner can be performed only intermittently. The acquisition and analysis of these samples is labor intensive, a problem that grows in significance as the frequency of sampling increases. 


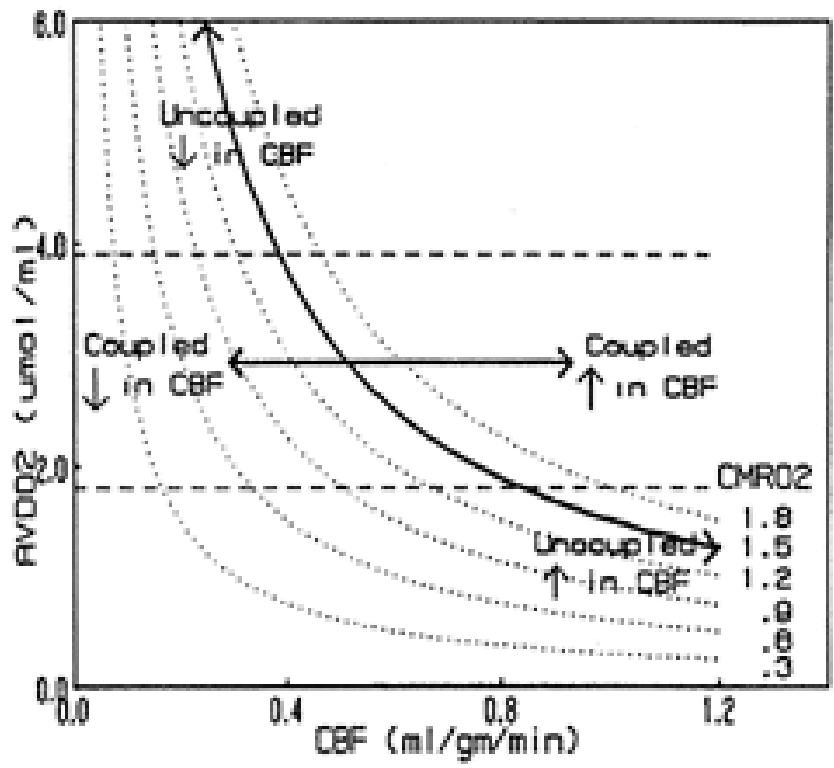

Fig. 1. Graph showing the relationship among $\mathrm{AVDO}_{2}, \mathrm{CBF}$, and $\mathrm{CMRO}_{2}$ values. Reproduced with permission of Robertson, et al.

\section{Jugular Venous Oxygen Saturation}

Several of the drawbacks of $\mathrm{AVDO}_{2}$ monitoring may be overcome by using continuous $\mathrm{SjvO}_{2}$ monitoring. This technique requires that a fiberoptic oxygen-sensing catheter be placed in the jugular bulb ${ }^{7}$ (Fig. 2). A drop in $\mathrm{SjvO}_{2}$ to below $50 \%$ for at least 10 minutes has been identified as a critical threshold. The development of such episodes correlates with a worsened outcome in patients who have sustained TBI, especially if they occur more than once during a patient's course of treatment. ${ }^{1}$ Episodes of jugular venous oxygen desaturation have been reported in $40 \%$ of severely head-injured patients. Importantly, most desaturation events last less than an hour, making it unlikely that they would have been detected by intermittent monitoring techniques such as $\mathrm{AVDO}_{2}$ measurement.

In comparison with monitoring of $\mathrm{AVDO}_{2}$, jugular venous oximetry offers the advantages of a continuous and real-time display of the parameter of interest. Both $\mathrm{AVDO}_{2}$ and $\mathrm{SjvO}_{2}$ monitoring require cannulation of the jugular bulb. In addition, $\mathrm{SjvO}_{2}$ monitoring is susceptible to artifacts caused by baseline drift of the catheter or by lodging of the sensor tip of the catheter against the wall of the vein. ${ }^{9}$ A drop in $\mathrm{SjvO}_{2}$ to below $50 \%$ requires that the possibility of such artifacts be eliminated by adjusting the position of the catheter and/or of the patient's head, as well as by checking the calibration of the catheter against a sample of jugular venous blood. Even if no episodes of jugular venous desaturation occur, $\mathrm{SjvO}_{2}$ catheters should be calibrated every 8 to 24 hours to minimize spurious readings caused by baseline drift.

\section{REGIONAL CEREBRAL METABOLISM}

Analysis of blood obtained from the jugular bulb provides a composite value of hemoglobin saturation for blood exiting the entire brain. However, in patients with severe TBI considerable regional heterogeneity of cere-

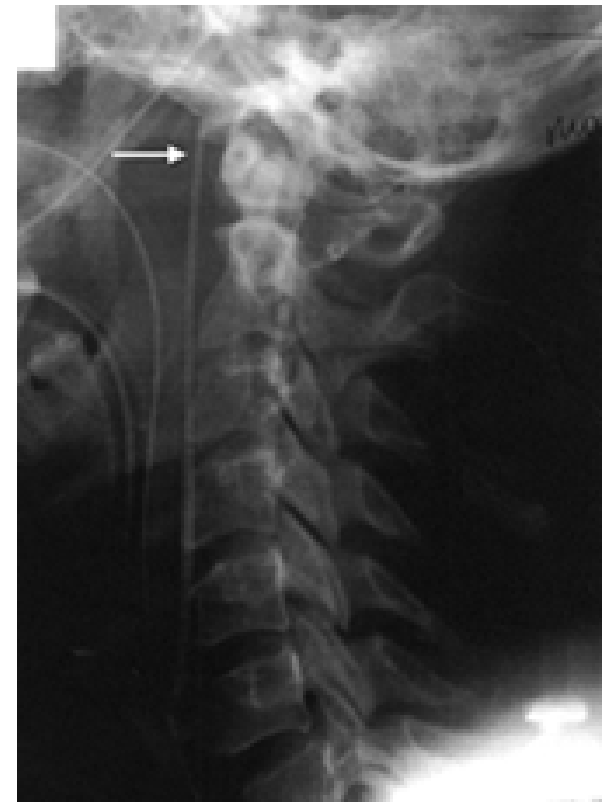

Fig. 2. Lateral cervical spine radiograph demonstrating position of the jugular bulb catheter (arrow).

bral metabolism is often demonstrated. ${ }^{4}$ Global monitors such as jugular bulb catheters may not reveal the presence of regions of severely depressed metabolism if the abnormal metabolic profile generated by such areas is diluted and masked by the greater volume of blood flowing from relatively normal brain. Discrepancies in values obtained simultaneously from bilateral $\mathrm{SjvO}_{2}$ catheters have also been reported. ${ }^{10}$

\section{Brain Tissue Oxygen Tension}

Fortunately, various techniques for monitoring regional cerebral metabolism have become available. Small catheters originally developed for direct and continuous monitoring of arterial blood $\mathrm{PO}_{2}$ soon became invaluable for monitoring $\mathrm{PbtO}_{2}$. These catheters are inserted directly into the brain parenchyma, in a fashion similar to that used for the insertion of fiberoptic or miniaturized strain gauge catheters for measuring intracranial pressure (Fig. 3). They may be inserted during a craniotomy or via a burr hole or twist-drill hole. One type of catheter, which has already been approved by the United States Food and Drug Administration, measures $\mathrm{PO}_{2}, \mathrm{PCO}_{2}, \mathrm{pH}$, and temperature. Another type, which is used widely in Europe but has not yet been approved by the Food and Drug Administration, measures only $\mathrm{PO}_{2}$ and requires that a second small temperature probe be inserted to permit automatic temperature correction of the $\mathrm{PO}_{2}$ measurements.

Brain tissue oxygen tension values reflect the balance between oxygen delivery to the cerebral extracellular space and oxygen consumption by cerebral tissue. Reported "normal" and critical values vary depending on the type of catheter used. ${ }^{11}$ Analysis of data obtained from authors who used the European catheter suggests that "normal" $\mathrm{PbtO}_{2}$ may be approximately $35 \mathrm{~mm} \mathrm{Hg}$ or higher and that a critical value for poor outcome or death may be approximately 6 to $10 \mathrm{~mm} \mathrm{Hg.}{ }^{11}$ 


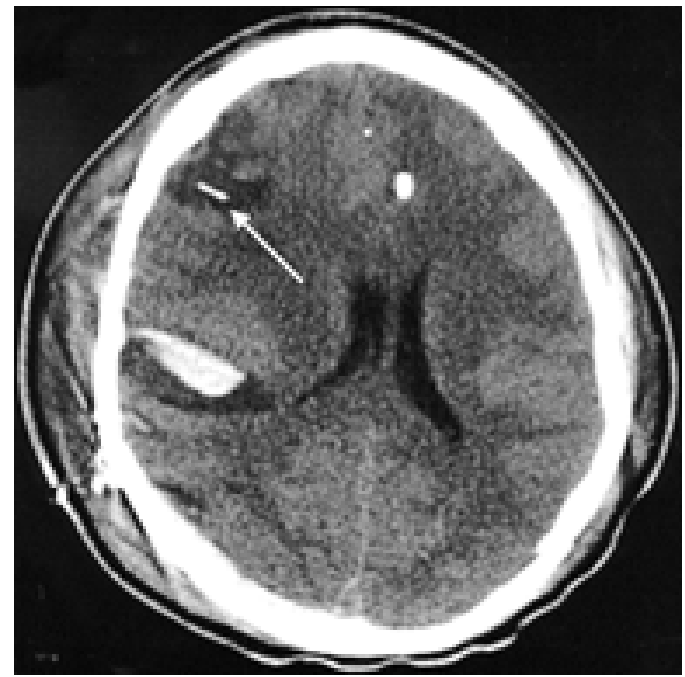

Fig. 3. Axial computerized tomography scan revealing placement of the $\mathrm{PbtO}_{2}$ catheter (arrow) in the region of abnormal hypodensity.

Although the major drawback of this technique is that the catheters must be inserted into the brain parenchyma, insertion-related hemorrhagic and infectious complications are quite rare. Moreover, the catheters seem to perform well, causing little baseline drift and further offsetting the potential risks associated with their insertion. ${ }^{11,12}$

This stability of performance has led some investigators to suggest that $\mathrm{PbtO}$ monitoring is superior to $\mathrm{SjvO}_{2}$ monitoring for detecting ischemic events in head-injured patients. ${ }^{3,12}$ However, such investigations overlook the fact that $\mathrm{SjvO}_{2}$ and $\mathrm{PbtO}_{2}$ catheters differ fundamentally in the type of data each provides. The former measures global cerebral metabolism, as discussed above. On the other hand, $\mathrm{PbtO}$ catheters sample only a very small volume of brain tissue, which makes them quite useful for obtaining regional measurements. If homogeneity of metabolism is an expected finding in the brain of a patient who has sustained TBI (for example, because the initial computerized tomography scan revealed no contusions or other sizeable lesions), then the $\mathrm{PbtO}_{2}$ data can probably be interpreted as indicative of the status of global metabolism. However, if the probe lies near a contused area, then the data that it provides may reflect the metabolic status only of the area of abnormality, which may be very different from that found in most of the brain.

We have compared $\mathrm{SjvO}_{2}$ and $\mathrm{PbtO}_{2}$ as indicators of cerebral ischemia in 58 patients with severe TBI. ${ }^{2}$ Ischemic episodes were defined as all decreases of $\mathrm{SjvO}_{2}$ to less than $50 \%$ and/or of $\mathrm{PbtO}_{2}$ to less than $8 \mathrm{~mm} \mathrm{Hg}$. Brain tissue oxygen tension monitoring detected $64 \%$ of these episodes, and $\mathrm{SjvO}_{2}$ monitoring detected $70 \%$. Jugular venous oxygen saturation more consistently reflected a decrease in oxygenation from hyperventilation, whereas $\mathrm{PbtO}_{2}$ was more sensitive to changes in arterial $\mathrm{PO}_{2}$. These data suggest that $\mathrm{PbtO}_{2}$ and $\mathrm{SjvO}_{2}$ monitoring are best considered as complementary, rather than competing, techniques. The regional nature of $\mathrm{PbtO}_{2}$ monitoring is put to optimal use by placing $\mathrm{PbtO}_{2}$ probes in tissue most vulnerable to ischemia but that may be salvagable with aggressive intervention. Several groups are currently in- vestigating whether monitoring $\mathrm{PbtO}_{2}$ combined with aggressive treatment of critically low values, especially during the first hours after injury, improves outcome after TBI. ${ }^{5}$

\section{CONCLUSIONS}

Monitoring of cerebral oxidative metabolism has evolved from indirect and intermittent measurement of the amount of oxygen consumed by the whole brain to direct measurement of cerebral oxygen tension in specific areas of interest. Appreciation of the unique characteristics of the various currently available methods maximizes the usefulness of the information provided and may thereby help patients achieve the best possible outcome.

\section{References}

1. Gopinath SP, Robertson CS, Contant CF, et al: Jugular venous desaturation and outcome after head injury. J Neurol Neurosurg Psychiatry 57:717-723, 1994

2. Gopinath SP, Valadka AB, Uzura M, et al: Comparison of jugular venous oxygen saturation and brain tissue $\mathrm{PO}_{2}$ as monitors of cerebral ischemia after head injury. Crit Care Med 27: 2337-2345, 1999

3. Kiening KL, Unterberg AW, Bardt TF, et al: Monitoring of cerebral oxygenation in patients with severe head injuries: brain tissue $\mathrm{PO}_{2}$ versus jugular vein oxygen saturation. J Neurosurg 85:751-757, 1996

4. Marion DW, Darby J, Yonas H: Acute regional cerebral blood flow changes caused by severe head injuries. J Neurosurg 74: 407-414, 1991

5. Menzel M, Doppenberg EM, Zauner A, et al: Increased inspired oxygen concentration as a factor in improved brain tissue oxygenation and tissue lactate levels after severe human head injury. J Neurosurg 91:1-10, 1999

6. Raichle ME, Grubb RLJ, Gado MH, et al: Correlation between regional cerebral blood flow and oxidative metabolism. In vivo studies in man. Arch Neurol 33:523-526, 1976

7. Ritter AM, Gopinath SP, Contant C, et al: Evaluation of a regional oxygen saturation catheter for monitoring $\mathrm{SjvO}_{2}$ in head injured patients. J Clin Monit 12:285-291, 1996

8. Robertson CS, Narayan RK, Gokaslan ZL, et al: Cerebral arteriovenous oxygen difference as an estimate of cerebral blood flow in comatose patients. J Neurosurg 70:222-230, 1989

9. Sheinberg M, Kanter MJ, Robertson CS, et al: Continuous monitoring of jugular venous oxygen saturation in head-injured patients. J Neurosurg 76:212-217, 1992

10. Stocchetti N, Paparella A, Bridelli F, et al: Cerebral venous oxygen saturation studied with bilateral samples in the internal jugular veins. Neurosurgery 34:38-43, 1994

11. Valadka AB, Gopinath SP, Contant CF, et al: Relationship of brain tissue $\mathrm{PO}_{2}$ to outcome after severe head injury. Crit Care Med 26:1576-1581, 1998

12. van Santbrink H, Maas AI, Avezaat CJ: Continuous monitoring of partial pressure of brain tissue oxygen in patients with severe head injury. Neurosurgery 38:21-31, 1996

Manuscript received September 15, 2000.

Accepted in final form November 15, 2000.

Supported by National Institutes of Health Grant NS-38660

Address reprint requests to: Alex B. Valadka, M.D., Department of Neurosurgery, Baylor College of Medicine, 6560 Fannin, Suite 944, Houston, Texas 77030. email: avaladka@bcm.tmc.edu. 